\title{
SCALE MODELING OF SNOW-AVALANGHE IMPACT ON STRUCTURES
}

\author{
By T. E. LANG and J. D. Dent \\ (Department of Civil Engineering and Engineering Mechanics, Montana State University, \\ Bozeman, Montana 597 I 7, U.S.A.)
}

\begin{abstract}
Small-scale modeling of flow and impact of snow avalanches is demonstrated to be both feasible and accurate. Geometric, kinematic, and force variables are scaled correctly under equivalence of Froude number between prototype and model using sifted snow as the model fluid. Physical and computersimulated impact processes show correspondence, so that computer modeling is demonstrated to be a viable tool in flow and impact predictions.

RÉsumé. Modélisation de l'impact d'une avalanche de neige sur un obstacle. On démontre que la modélisation à petite échelle de l'écoulement et de l'impact des avalanches de neige est à la fois possible et précise. Les variables dynamiques, cinématiques et géométriques sont correctement représentées par l'intermédiaire d'un nombre de Froude à respecter entre le modèle et la grandeur nature de la neige tamisée servant de fluide dans le modèle. Les processus d'impact physique et simulés par l'ordinateur montrent une bonne correspondance de sorte qu'il est prouvé que l'ordinateur est un outil capable de prévoir écoulement et impacts.

Zusammenfassung. Modellierung des Aufpralls von Schneelawinen auf Bauwerke. Eine Modellicrung des Flusses und Aufpralls von Schneelawinen in verkleinertem Masstab erweist sich als zweckmässig und genau. Die geometrischen, kinematischen und dynamischen Variablen werden bei gleichwertigen Froude-Zahlen zwischen Prototyp und Modell unter Benutzung von gesiebtem Schnee als Modellmaterial richtig bemessen. Physikalische und im Rechner simulierte Aufprallprozesse zeigen Übereinstimmung; Simulation im Rechner erweist sich damit als wirksames Mittel zur Voraussage von Fluss und Aufprall.
\end{abstract}

\section{INTRODUGTION}

In the fluid-dynamic modeling of sheet or channel flow, correspondence between the model and the full-scale process is assured if Reynolds and Froude numbers can be made equal in model and prototype. In order to do this exactly, a different fluid must be used in the model from that of the prototype in order to model kinematic viscosity correctly. However, this is generally not practicable, so the usual approach is to model the dominant scaling parameter, Froude number, and use analytical methodology to adjust for the lack of equivalence in Reynold's number.

With regard to snow avalanche flow, in which modeling techniques would be beneficial, no analytical tool has been available to supplement the scaling laws to establish the rationale for modeling. Computer codes which have been reported recently, designated AVALNCH (Lang and others, I979) and SMAC (Pedersen and others, 1979), provide analytical means for the establishment of criteria for avalanche modeling. Of particular interest is the construction of criteria to model the forces and pressures of avalanche impact upon structures and obstacles.

\section{COMPUTER PROGRAM VARIABLES}

In the computer programs two basic variables define the flow of snow. One is the kinematic viscosity $\nu$ which is related to internal-energy dissipation. The second is the friction coefficient $f$ which defines the surface slip velocity $U_{\mathrm{s}}$ as a fraction of the main stream flow $U_{0}$. The explicit relationship is

$$
U_{\mathrm{s}}=U_{0}(\mathrm{I}-f) .
$$

In addition, we define terminal flow as the steady value attained by the mainstream velocity based upon slope angle, depth of flow, and specific values of $v$ and $f$. Terminal velocity has been computed by Lang and others (1978) using program AVALNCH over a limited range of parameters. 
The following relationship can be established for shear stress $T_{0}$ at the base of the flow by using Equation ( $\mathrm{I}$ ) to define velocity gradient and selecting the Newtonian viscosity law for shear stress in fluid:

$$
\frac{T_{0}}{\rho}=\nu \frac{\partial u}{\partial y} \approx \nu \frac{2 U_{0} f}{\delta_{y}} .
$$

In Equation (2) $\rho$ is the material density and $\delta_{y}$ is the vertical dimension of the finite-difference grid used in the numerical representation of the flow in the computer program (Lang and Brown, 1980).

\section{EXPERIMENTAL AND COMPUTER-MODELING GRITERIA}

To develop a composite evaluation of snow-avalanche modeling, we draw upon data from published sources in addition to test data we have obtained. To standardize the evaluation we select a slope angle of $45^{\circ}$, which is common to several geometries used in published results.

One comparison which establishes the accuracy of the computer codes to model snow impact has been reported by Pedersen and others (1979) and is made possible by original experimentation of Salm (1964). One-meter-deep blocks of high-density snow $\left(570 \mathrm{~kg} / \mathrm{m}^{3}\right)$ were slid down a $45^{\circ} \mathrm{ramp}$ and impacted at $12 \mathrm{~m} / \mathrm{s}$ against a force-measuring target. Average normal stress measured was $\mathrm{I} 65 \mathrm{kN} / \mathrm{m}^{2}$. In approximating this three-dimensional impact by a two-dimensional approximation using program SMAC, Pedersen and others (1979) report an average stress of $200 \mathrm{kN} / \mathrm{m}^{2}$. The difference is $21 \%$ too high, but this is consistent with the s.dded dimensional constraint imposed on the computed result.

We establish the following specifications as representative of a nominal prototype avalanche associated with dry snow-pack conditions. If flow depth is taken as $\mathrm{r} .0 \mathrm{~m}$, then with kinematic viscosity $\nu=0.5 \mathrm{~m}^{2} / \mathrm{s}$ and surface friction coefficient $f=0.5$, terminal velocity on a $45^{\circ}$ slope is approximately $30 \mathrm{~m} / \mathrm{s}$. For this range of parameters, average normal stress of impact is reported by Schaerer (1973) as being on the order of $200 \mathrm{kN} / \mathrm{m}^{2}$ from tests at Rodgers Pass, Canada, and $240 \mathrm{kN} / \mathrm{m}^{2}$ reported by Lang and Brown (1980) using program AVALNCH. Reynold number $(R e)_{\mathrm{p}}$ and Froude number $(F r)_{\mathrm{p}}$ for this prototype configuration are

$$
\begin{aligned}
& (R e)_{\mathrm{p}}=\frac{U(4 h)}{\nu}=240 \\
& (F r)_{\mathrm{p}}=\frac{U}{(g h)^{0.5}}=9.6 .
\end{aligned}
$$

A series of tests were conducted in which sifted snow of density $\rho=360 \mathrm{~kg} / \mathrm{m}^{3}$ was released onto a track $2.5 \mathrm{~m}$ long, $0.3 \mathrm{~m}$ wide, and with $0.05 \mathrm{~m}$ high side walls. The snow volumes released were $0.50 \mathrm{~m}$ in length, $0.30 \mathrm{~m}$ wide, and of depths $h=0.03,0.05$, and $0.07 \mathrm{~m}$. The track surface consisted of glued sand of $1.0 \mathrm{~mm}$ grain diameter to simulate snow of the same mean diameter as that released. The tests were conducted in an upright freezer at $-10^{\circ} \mathrm{C}$ and the slope angle of the track was variable. Markings along the track provided means of estimating flow speed from $16 \mathrm{~mm}$ filming of each test (Fig. I). A target having a frontal area $0.30 \mathrm{~m}$ wide and $0.05 \mathrm{~m}$ high was placed at the terminal end of the track. This rigid target was constructed from balsa wood and styrofoam weighing $0.024 \mathrm{~kg}$, so that inertial effects of the target were minimized (Fig. 2). Two cantilever plates fitted with strain gages were calibrated to measure total force on the target.

With the track set at $45^{\circ}$ slope, terminal velocity was found to be $3.7 \mathrm{~m} / \mathrm{s}$ and the flow depth $h$ was o.or I m, independent of the depth of the snow in the released volume. Computer modeling of the flow using program AVALNCH required $v=0.017 \mathrm{~m}^{2} / \mathrm{s}$ and $f=0.017$ 


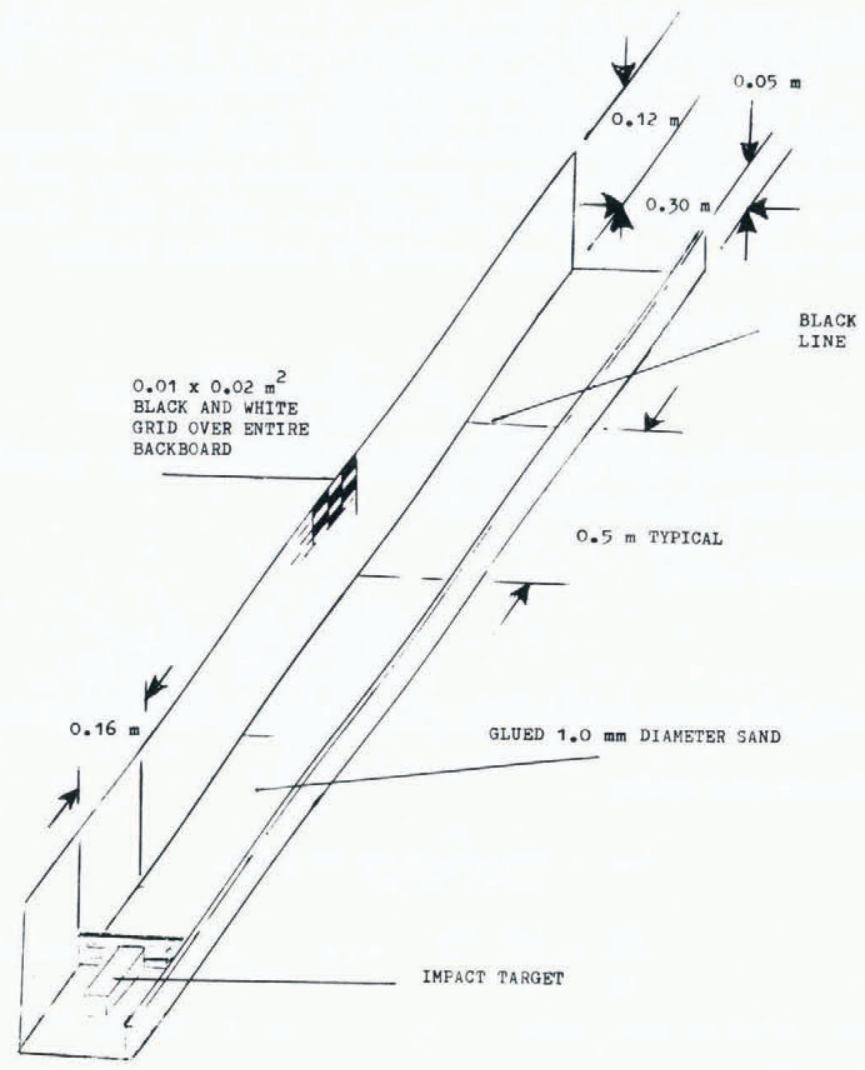

Fig. I. Track and target configuration.

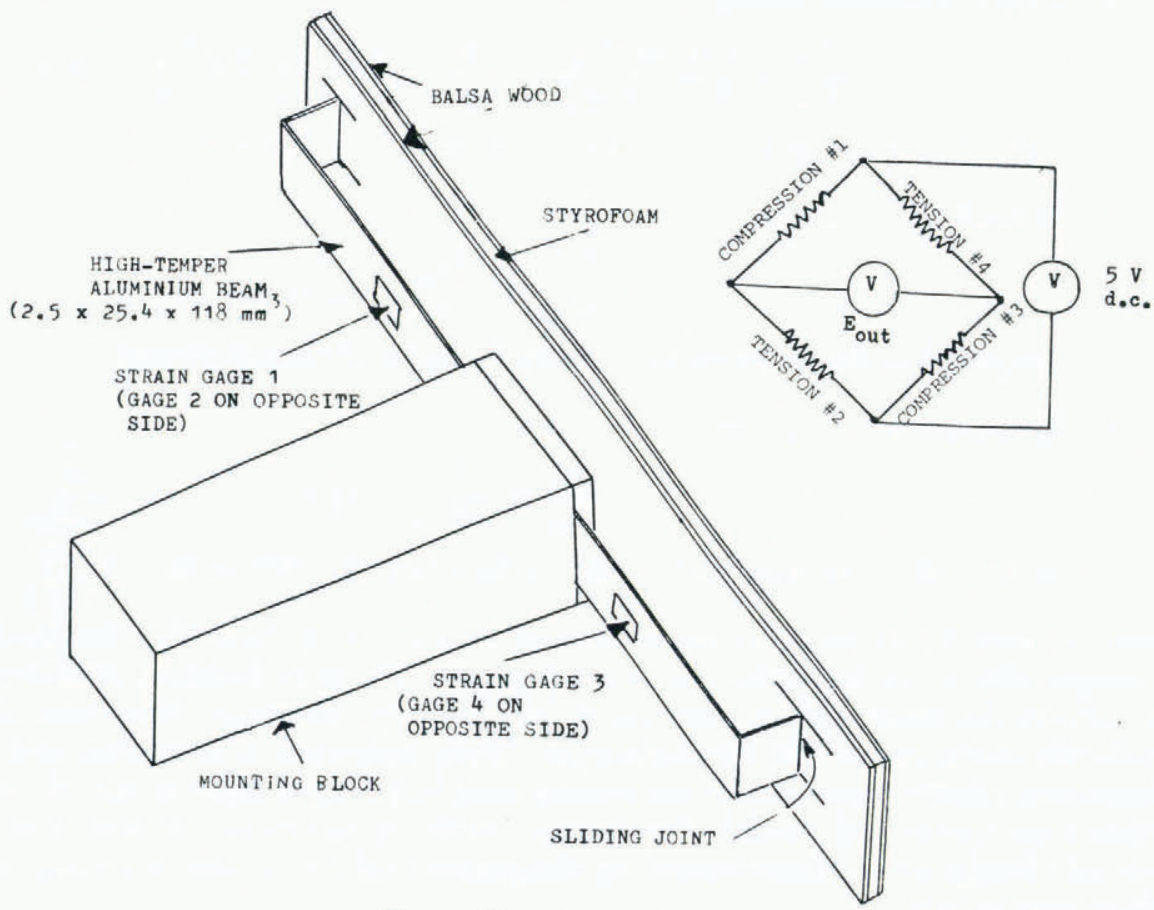

Fig. 2. Target for snow-impact tests. 
for duplication of the velocity along the path. With these parameter values, Reynolds and Froude number $\left((R e)_{\mathrm{m}}\right.$ and $\left.(F r)_{\mathrm{m}}\right)$ were computed to be $\mathrm{I} 2.2$ and $\mathrm{I}$ I.2 respectively.

The ratio of Froude numbers $(F r) \mathrm{p} /(F r)_{\mathrm{m}}=0.86$ is close to unity, so that a scaling law based upon equivalence of Froude number is considered further.

(a) Geometric scaling

$$
L_{r}=\frac{h_{\mathrm{p}}}{h_{\mathrm{m}}}=\frac{\mathrm{I} \text { ooo }}{\mathrm{I} \mathrm{I}}=90.9,
$$

which sets the scale factor for subsequent calculations. $h_{\mathrm{p}}$ and $h_{\mathrm{m}}$ are the prototype and model flow depths respectively.

(b) Kinematic scaling

$$
\frac{U_{\mathrm{op}}}{U_{0 \mathrm{~m}}}=\frac{3 \mathrm{o}}{3.7}=8 . \mathrm{I} \text {, }
$$

compared to an exact value $\sqrt{ } L_{r}=9.53$ ( $14.6 \%$ difference).

(c) Normal-stress scaling

$$
\begin{aligned}
\sigma_{\mathrm{m}} & =\frac{\text { 10 }}{(0.01 \mathrm{I})(0.30)}=3030, \\
\frac{\sigma_{\mathrm{p}}}{\sigma_{\mathrm{m}}} & =\frac{240000}{3030}=79.2 \quad(\sigma \text { denotes normal stress }),
\end{aligned}
$$

compared to the exact $\left(\rho_{\mathrm{p}} / \rho_{\mathrm{m}}\right) L_{r}=90.9$ (12.9\% difference) where we assume $\rho_{\mathrm{p}}=\rho_{\mathrm{m}}$.

(d) Surface shear-stress scaling

$$
\frac{T_{\mathrm{p}}}{T_{\mathrm{m}}}=\frac{U_{\mathrm{op}} f_{\mathrm{p}} \nu_{\mathrm{p}} \delta_{y \mathrm{~m}}}{U_{0 \mathrm{~m}} f_{\mathrm{m}} \nu_{\mathrm{m}} y_{\mathrm{p}}}=\frac{30 \times 0.5 \times 0.5 \times 0.01 \mathrm{I}}{3.7 \times 0.017 \times 0.017 \times 1.0}=77.2,
$$

compared to the exact $\left(\rho_{\mathrm{p}} / \rho_{\mathrm{m}}\right) L_{r}=90.9$ (15.1 \% difference).

(e) Reynolds number scaling

$$
\frac{(R e)_{\mathrm{p}}}{(R e)_{\mathrm{m}}}=\frac{240}{\mathrm{I} 2.2}=19.7,
$$

compared to the exact value of unity (a factor of 19.7 different).

(f) Kinematic-viscosity scaling

$$
\frac{\nu_{\mathrm{p}}}{\nu_{\mathrm{m}}}=\frac{0.5}{0.015}=33.3,
$$

compared to the exact $L r^{\frac{3}{2}}=867$ (a factor of 26.0 different).

From (e) and (f) we see that the scaling of viscosity is in error by a factor of 26.0 , which is comparable to the Reynolds number mismatch. The non-modeling of kinematic viscosity also affects the lower surface shear stress (d); however, dominant correction of this must be attributed to the ratio of the friction factors. Thus, geometric, kinematical, and force or stress parameters closely approximate the scaling laws based upon equivalence of Froude number between prototype and model. Parameters involving kinematic viscosity which pertains to internal circulation and internal-energy dissipation tend not to scale correctly, unless internal adjustment occurs. 


\section{COMPUTER AND EXPERIMENTAL IMPACT GORRESPONDENCE}

Experimentally, total force on the target was recorded by output of the four-active-arm strain-gage bridge displayed on a storage oscilloscope, and the trace photographed. A total of four tests in which depth of released snow was varied were run with the track set at $45^{\circ}$ slope. Traces of the four tests are shown in Figure $3 \mathrm{a}$, showing the scatter, particularly that of the transient phase of each impact. However, by the time the snow had flowed to the target, depth of flow averaged $0.01 \mathrm{I} \mathrm{m}$ in all tests, and the flow velocity was $3.7 \mathrm{~m} / \mathrm{s}$. The force trace of each test was different because of differences in leading-edge slope and different distributions of small blocks of snow that had not disintegrated during the flow. Thus, a composite force profile which is an average of the four tests can be constructed, and is shown in Figure 4 .

In the computer, program AVALNCH was used to estimate the internal viscosity and the surface friction coefficient in order to duplicate the velocity distribution of the flow. These values were then used in program SMAC to represent the impact and material overflow of the target. In the computer simulation the target was represented as a rigid barrier, so that force transient response differs from the experimental profile. However, average force response between computer and experimental results agree well, as seen in Figure 4. Average force during the time period between $100 \mathrm{~ms}$ and $250 \mathrm{~ms}$ is $11.0 \mathrm{~N}$ experimentally, and $9.8 \mathrm{~N}$
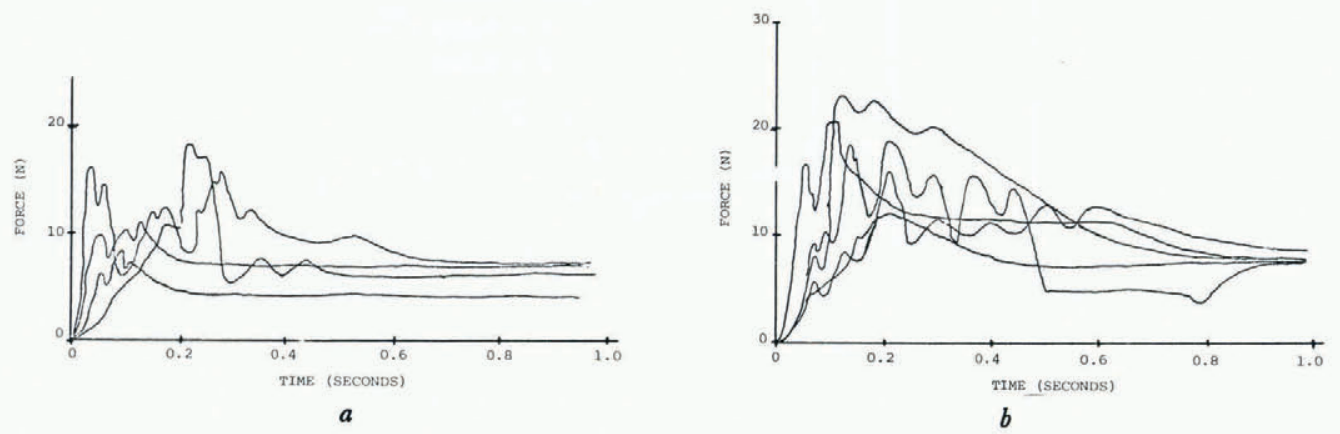

Fig. 3. Force traces of impacts. a. $45^{\circ}$ slope. b. $53 \cdot 5^{\circ}$ slope.

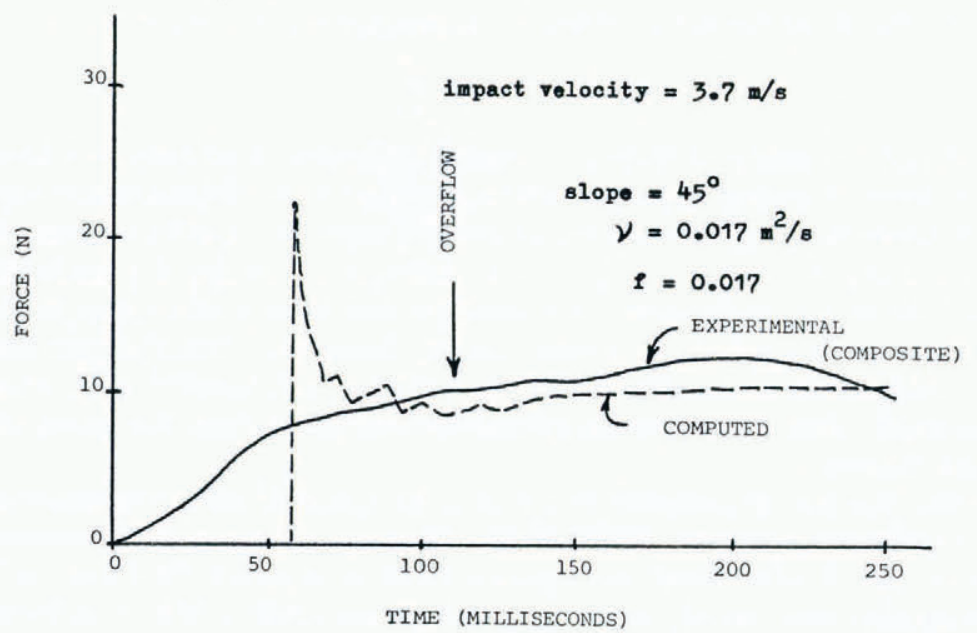

Fig. 4. Average experimental and computed normal force profiles of snow impact on a $45^{\circ}$ slope. 
in the simulation, which is an $\mathrm{I} \%$ difference. In comparing the average or steady forces on the impact barrier, effects of material compressibility are clearly unimportant. During steady flow a triangular wedge has already formed at the barrier and flow is established over the wedge. If compressibility enters into consideration, it would be during formation of the wedge which is during the transient phase of the force profile.

Using the same experimental procedure as already described, five tests were run with the track set at $53.5^{\circ}$ slope (Fig. $3 \mathrm{~b}$ ). Flow depth was, on average, o.or I $\mathrm{m}$ and the terminal velocity was $4.8 \mathrm{~m} / \mathrm{s}$. Computed and measured forces on the target are shown in Figure 5 . Average experimental force was $14.5 \mathrm{~N}$, and the average computed force was $15.5 \mathrm{~N}(6.9 \%$ difference). For these results viscosity $v=0.015 \mathrm{~m}^{2} / \mathrm{s}$ and friction coefficient $f=0.015$.

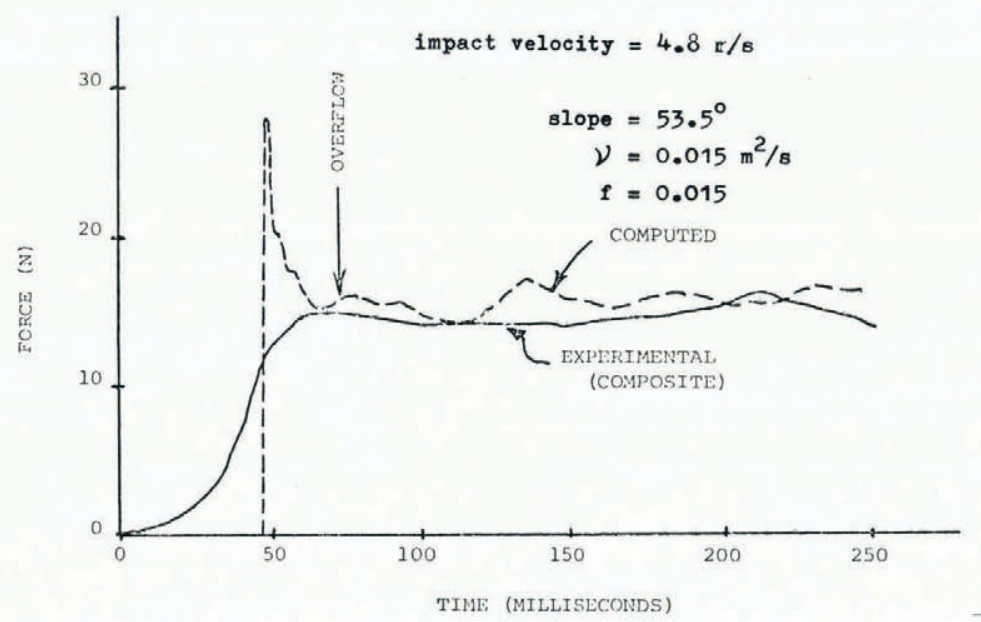

Fig. 5. Average experimental and computed normal force profiles of snow impact on a $53.5^{\circ}$ slope.

On the basis of a number of flow and impact tests described here, we have developed a graph showing the relationship between avalanche flow depth and kinematic viscosity (Fig. 6). For deep flows, kinematic viscosity is asymptotic to a value of $0.5 \mathrm{~m}^{2} / \mathrm{s}$ and falls to lower values for shallower flow depths. For $\nu=0.5 \mathrm{~m}^{2} / \mathrm{s}$ the snow is nominally dry midwinter hard-pack. Values of $\nu$ as low as $0.35 \mathrm{~m}^{2} / \mathrm{s}$ have been used for soft snow avalanches, and values greater than $0.5 \mathrm{~m}^{2} / \mathrm{s}$ have been used with wet-snow cases. Numerical experimentation on a number of avalanche configurations has shown that in setting $\nu=f$, numerically, satisfactory results have been obtained. The impact results given here are based upon the numerical equivalence of viscosity and friction.

We note that the use of parameters $f$ and $\nu$, as specified here, correspond to snow-flow modeling by computer program AVALNCH. Recent refinements in snow-flow modeling have resulted in use of other fluid mechanisms such as reported by Dent and Lang (1980). In the present application, use of $f$ and $\nu$ to maintain the velocity of flow at impact has proved satisfactory. 


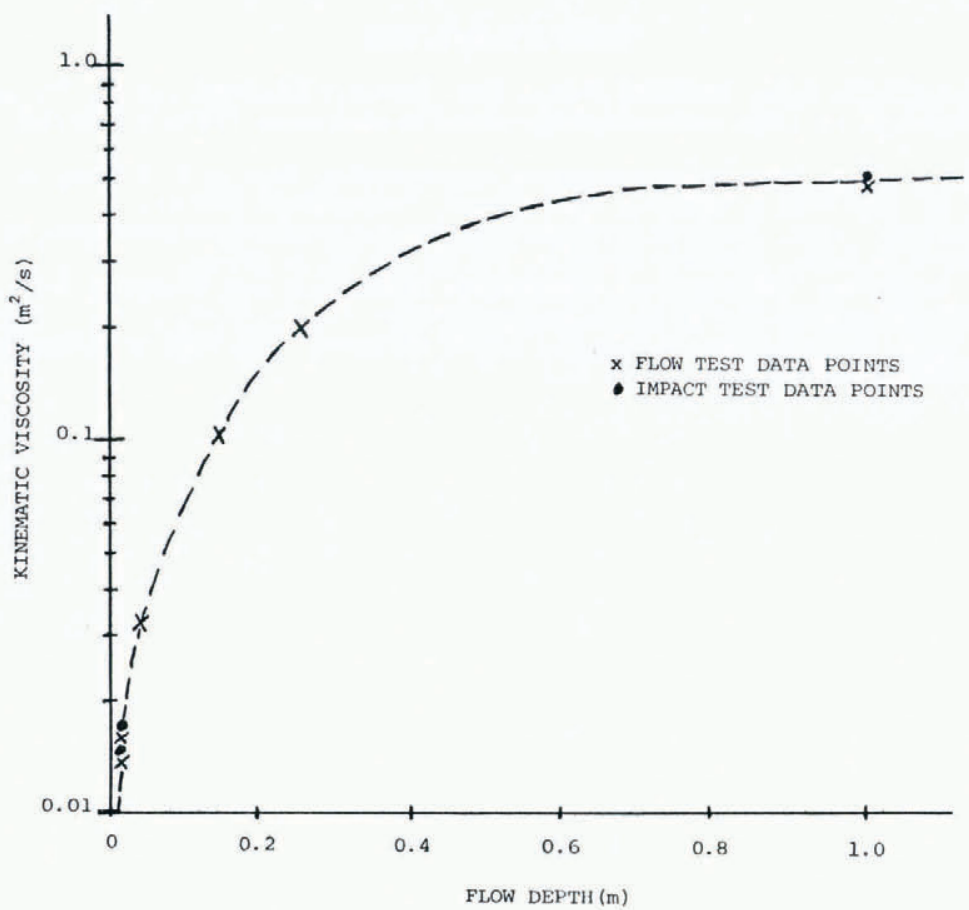

Fig. 6. Kinematic viscosity of flowing snow as a function of flow depth using program AVALNCH.

\section{Conclusions}

Small-scale modeling of snow avalanches is shown to be feasible for geometric, kinematic, and force and stress variables based upon numerical equivalence of the Froude number between prototype and model. Fluid for the model flow is sifted snow with density of the same order as that of the prototype. Use of sifted snow violates the model laws for scaling of viscous properties and, hence, also of Reynold's number. Viscosity affects primarily internalenergy dissipation due to internal circulation in the flow, which has negligible influence on the force and dimension variables relating to impact. For flow modeling the error in viscosity scaling is offset by the scaling of the surface friction coefficient. Computer programs AVALNCH and SMAC accurately predict model response by the correct scaling of viscosity and friction, as is determined by comparison with corresponding experimental results. Thus, these computer programs provide analytical methods for continued work in model and prototype studies of avalanche-flow and impact processes.

\section{AGKnowledgements}

The authors wish to express their thanks for support of this work to Dr M. Martinelli, Jr, group leader for snow research at the Rocky Mountain Forest and Range Experiment Station, Fort Collins, Colorado (Agreement No. I6-884-CA) and Professor Theodore Williams, Department Head of Civil Engineering and Engineering Mechanics, Montana State University, Bozeman, Montana. 


\section{REFERENCES}

Dent, J. D., and Lang, T. E. 1980. Modeling of snow flow. Journal of Glaciology, Vol. 26, No. 94, p. 131-40.

Lang, T. E., and Brown, R. L. 1980. Snow-avalanche impact on structures. Fournal of Glaciology, Vol. 25, No. 93, p. $445-55$.

Lang, T. E., and others. 1979. Numerical simulation of snow-avalanche flow, by T. E. Lang, K. L. Dawson, and M. Martinelli, Jr. U.S. Dept. of Agriculture. Forest Service. Research Paper RM-205.

Pedersen, R. R., and others. 1979. Forces on structures impacted and enveloped by avalanches, by R. R. Pedersen, J. D. Dent, and T. E. Lang. Fournal of Glaciology, Vol. 22, No. 88, p. 529-34.

Salm, B. 1964 . Anlage zur Untersuchung dynamischer Wirkungen von bewegtem Schee. Zeitschrift für angewandte Mathematik und Physik, Vol. 15, Fasc. 4, p. 357-75.

Schaerer, P. A. 1973. Observations of avalanche impact pressures. U.S. Dept. of Agriculture. Forest Service. General Technical Report RM-3, p. $5^{\mathrm{I}-54}$. 